\title{
Chapter 14 \\ Challenges Regarding the Protection of Animals During Warfare
}

\author{
Jérôme de Hemptinne
}

\begin{abstract}
The chapter turns to the treatment of animals in one of the two classical divisions of international law, the laws of war, examining the protection of animals during hostilities. De Hemptinne explains that international humanitarian law (IHL) does not contain explicit rules to mitigate the suffering of animals in armed conflict. However, the overall evolution of law's approach to animals, notably its recognition of them as sentient beings, appears to allow for a progressive interpretation of IHL so as to constrain acts of violence against animals in war. The rules on the protection of civilian objects and on the environment, the proportionality principle, or the options for declaring demilitarized zones could all be activated to this end.
\end{abstract}

\section{Introduction}

In times of war, the first instinct is to relieve the suffering of human beings. Environmental and animal interests are always pushed into the background. However, warfare strongly affects natural resources, including animals, which makes animal issues a matter of great concern. Habitat destruction and the resulting disappearance of animals often threaten the survival of populations affected by hostilities. Furthermore, over the last 50 years, certain species have been vanishing at a rapid rate because of wars, often with disastrous effects on the food chain and on the ecological balance. Indeed, during this period, $80 \%$ of armed conflicts have taken place in countries-such as Afghanistan, Burundi, Central African Republic, Congo,

Revised version of the original published article "The Protection of Animals during Warfare" by Jérôme de Hemptinne, American Journal of International Law Unbound, Volume 111, 2017, pp. 272-276. The original article was published as an Open Access article, distributed under the terms of the Creative Commons Attribution licence (http://creativecommons.org/licenses/ by/4.0/).

J. de Hemptinne (ه)

University of Geneva, Geneva, Switzerland

(C) The Author(s) 2020

A. Peters (ed.), Studies in Global Animal Law, Beiträge zum ausländischen

öffentlichen Recht und Völkerrecht 290,

https://doi.org/10.1007/978-3-662-60756-5_14 
Kenya, Rwanda, Uganda or Vietnam - that contain areas of high global species diversities. ${ }^{1}$ Belligerents even take advantage of the chaotic circumstances of war in order to poach protected species and to engage in the trafficking of expensive animal products. While generating billions of dollars each year-which are, in part, invested in warfare and the acquisition of weapons - such poaching and trafficking allows armed groups to grow and to reinforce their authority over disputed territory. This fuels a cycle of violence and ultimately threatens peace and security in these areas. States have also trained, and continue to train, certain animals-principally marine mammals such as bottlenose dolphins and California sea lions-to perform military tasks, like ship and harbour protection, or mine detection and clearance. Millions of horses, mules, donkeys, camels, dogs and birds are obliged to serve on various fronts (transport, logistics, or communications) and become particularly vulnerable targets.

However, being deeply anthropocentric, international humanitarian law (IHL) largely ignores the protection of animals. That said, some general principles could potentially provide minimum safeguards to animals during armed conflict. Moreover, a progressive interpretation of these principles, in light of developments in the welfare and rights of animals in peacetime, could significantly reinforce this protection. After having discussed the reasons underlying the silence of IHL on the protection of animals (Sect. 2), this chapter will outline the particular challenges that this issue creates in the context of the distinction between international armed conflicts (IACs) and non-international armed conflicts (NIACs) (Sect. 3). Finally, it will consider the main difficulties stemming from the rules governing the conduct of hostilities (Sect. 4), and from the protective regime offered by the 1949 Geneva Conventions (GCs) $)^{2}$ (Sect. 5).

\section{The Silence of IHL}

Despite the fact that animals are among those affected by armed conflicts, IHL does not directly deal with the question of their protection. As we will see below, animals are only indirectly addressed as civilian objects or as part of the natural environment. Three reasons might explain IHL's lack of interest in the welfare of animals. First, the main conventions regulating armed conflicts were adopted at a time when legal entitlements for animals did not attract significant attention. Geared essentially towards the safeguarding of human beings, IHL was-and still remains today-an

\footnotetext{
${ }^{1}$ Hanson et al., 'Warfare in Biodiversity Hotspots' 2009, 578. See generally Daskin/Pringle, 'Warfare and wildlife declines in Africa's protected areas' 2018, 328-332.

${ }^{2}$ Geneva Convention (I) for the Amelioration of the Condition of the Wounded and Sick in Armed Forces in the Field, 12 August 1949, 75 UNTS 31. Geneva Convention (II) for the Amelioration of the Condition of Wounded, Sick and Shipwrecked Members of Armed Forces at Sea, 12 August 1949, 75 UNTS 85. Geneva Convention (III) relative to the Treatment of Prisoners of War, 12 August 1949, 75 UNTS 135. Geneva Convention (IV) relative to the Protection of Civilian Persons in Time of War, 12 August 1949, 75 UNTS 287.
} 
overwhelmingly anthropocentric body of law 'displaying a strong utilitarian flavour. ${ }^{3}$ Indeed, even the few IHL provisions restricting attacks against the natural environment were designed with a view to preserving the interests of human beings instead of the environment per se. ${ }^{4}$ The Christian roots of IHL might also explain such an anthropocentric attitude and the difficulty for this body of law to conceptualise the protection of the environment independently of human interests. Second, on a more pragmatic level, it is often argued that alleviating the extreme suffering of human beings during hostilities would be impaired should animal protection be put at the forefront. Devoting time, energy and money to protect animals would prevent using these resources for worthier human causes. Lastly, we should not underestimate the fact that, in peacetime, while acts of violence against human beings are, in principle, forbidden, the slaughtering of animals-in conformity with certain methods and procedures-is widely accepted and practised throughout the world. In this context, it might appear paradoxical that, in situations of armed conflict, where acts of violence against certain individuals, mainly combatants, are admitted and expected, acts of violence against animals might be strictly constrained.

Let us briefly respond to these three arguments. First, IHL cannot ignore the evolution of the status and protection that animals have acquired in many jurisdictions around the world. In the same way that the strengthening of human rights and the increased awareness of environmental challenges after the Second World War have impacted on the development of IHL, the increasing concern for animal welfare during the last decades should also progressively impose limits on belligerents' actions. This is even more so when we consider that, as recalled in the introduction, wars have disastrous effects on wildlife and, in particular, on protected species whose survival is directly threatened by hostilities. Second, contrary to what is often claimed, safeguarding animals does not necessarily interfere, or run contrary to, the protection of human beings. The two can often run in parallel without impacting negatively on each other. In any case, we will see that certain IHL principles — such as the principle of proportionality — are flexible enough to guarantee that human values prevail over animal interests when one is forced to choose between the two. Third, the apparent 'paradox of violence' outlined above must be evaluated in light of the following factors. Due to the increased importance of animal welfare, acts of cruelty against animals are now widely restricted and sanctioned in peacetime. Conversely, acts of violence against animals during warfare could, in theory, be legally committed when animals become military objectives. Moreover, the forms of violence allowed in peacetime are of a fundamentally different nature from those authorised during armed conflicts. Indeed, the former aims at satisfying human needs (for instance, food production or medical, pharmaceutical and chemical testing). In contrast, the latter is, in principle, dictated by military considerations. This delineation between different types of violence is, however, not that

\footnotetext{
${ }^{3}$ Schmitt, 'Green War' 1997, 6.

${ }^{4}$ Ibid., 69 .
} 
straightforward: the slaughtering of animals for human uses also occurs in wartime, while certain forms of violence, which are usually committed in the chaotic circumstances of war-such as poaching and trafficking of species-can also take place during peacetime.

\section{The Distinction Between IACs and NIACs}

It is well know that the laws governing IACs - that is hostilities which oppose the armed forces of a state to another state-are much more developed than the laws regulating NIACs - that is hostilities of a certain intensity opposing armed groups to state armed forces or armed groups between themselves. In IACs, animals could, in theory, benefit from the protection offered by advanced IHL rules contained in the GCs and in the 1977 Additional Protocol I (AP I). ${ }^{5}$ Animals should also benefit from the fact that states possess developed institutional machinery, well-organised military forces, and sophisticated technologies that should improve the respect of these rules. The situation is, however, different in NIACs owing to legal and practical difficulties.

From a legal perspective, it should be recalled that only minimal conventional rules apply to NIACs (i.e. common Article 3 to the GCs and Additional Protocol II $\left.(\text { AP II })^{6}\right)$. That said, the recent development of customary IHL has narrowed the differences in regulation between IACs and NIACs. For instance, it is now widely accepted that the general rules governing the protection of civilian objects-namely, the principles of military necessity/humanity, distinction and proportionality-apply to all types of armed conflicts. This is also true for the rules protecting enemy property from wanton destruction ${ }^{7}$ and objects indispensable to the survival of the civilian population, ${ }^{8}$ and for the rules prohibiting the use of certain weapons, ${ }^{9}$ such as biological or chemical weapons. This evolution is crucial, because, as we will see in Sect. 3 below, all of these rules could be interpreted as providing minimum protection for animals, should they be treated as objects. In contrast, it is unclear whether the special protection accorded to the environment by Articles 35(3) and $55(1)$ of AP I-which encompasses wildlife ${ }^{10}$ - applies in NIACs within the state

\footnotetext{
${ }^{5}$ Protocol Additional to the Geneva Conventions of 12 August 1949, and relating to the Protection of Victims of International Armed Conflicts (Protocol I), 8 June 1977, 1125 UNTS 3.

${ }^{6}$ Protocol Additional to the Geneva Conventions of 12 August 1949, and relating to the Protection of Victims of Non-International Armed Conflicts (Protocol II), 8 June 1977, 1125 UNTS 609.

${ }^{7}$ GC I, 1949 (n. 2), art. 50. GC II, 1949 (n. 2), art. 51. GC IV, 1949 (n. 2), art. 147.

${ }^{8}$ AP I, 1977 (n. 5), art. 54.

${ }^{9}$ AP I, 1977 (n. 5), art. 35(2) \& art. 51(4).

${ }^{10}$ Roscini, 'Animals and the Law of Armed Conflict' 2017, 61.
} 
where such a conflict is taking place. ${ }^{11}$ This clearly reflects the reluctance of governments to accept that heavy constraints be imposed on them to conduct hostilities against rebels on their national territories. It could, however, be argued that the environment should always be safeguarded in NIACs when damages caused to it also affect other states. In this context, since wildlife is usually not confined to the territory of a single state and since its destruction generally affects the ecological balance on a wide scale, one could reasonably argue that the provisions protecting the environment contained in AP I should always protect wildlife, including within the territory of a state which experiences a NIAC.

From a practical perspective, armed groups often have limited abilities to conform to highly sophisticated norms, in particular those protecting animals. Indeed, assessing the legality of incidental damage caused to animals is beset with difficulties. It requires environmental knowledge that even well-equipped state armed forces often do not possess, particularly when considering that these damages tend to manifest themselves in the long run and that they are often the indirect result of the destruction of certain habitats. We will see below how complex it is to factor animal considerations into the application of the main IHL principles, in particular, when evaluating proportionality. Furthermore, the logic which underlies IHLaccording to which the legitimate aim of belligerents is to weaken the military potential of the adversary ${ }^{12}$ - will often be called into question when armed groups are motivated by other goals, such as poaching protected species and engaging in the trafficking of animal products. Thus, in the context of NIACs, ensuring the respect of complex IHL rules protecting the basic needs of animals will often be very difficult to achieve in practice.

\section{The Conduct of Hostilities}

Civilian objects are protected during the conduct of hostilities unless and for such time that they are military objectives. ${ }^{13}$ Moreover, according to the principle of proportionality, collateral damage on civilian objects is permissible but only to the extent that it is not excessive in relation to the concrete and direct military advantage anticipated as the result of an attack. ${ }^{14}$ These basic principles raise three main delicate questions in relation to animals. First, could animals be treated as civilian objects for the purpose of IHL? Second, if the first question is answered in the affirmative, how should one undertake the balancing exercise required by the principle of proportionality when animal interests are at stake? Third, do the rules

\footnotetext{
${ }^{11}$ ICRC, 'Customary International Law Database: Rule 44', available at: https://ihl-databases.icrc. org/customary-ihl/eng/docs/v1.

${ }^{12}$ Sassòli, 'Challenges faced by non-state armed groups' 2014, 172.

${ }^{13} \mathrm{AP}$ I, 1977 (n. 5), art. 52(2).

${ }^{14}$ AP I, 1977 (n. 5), art. 51(5)(b) \& art. 57.
} 
on the conduct of hostilities adequately protect animals as 'inanimate objects'? If not, how could they be better treated?

With respect to the first question, it could be contended that the notion of 'objects' is limited to 'inanimate objects,' as exemplified by the list of objects cited in Article 52(3) of AP I, which mentions, among other things, places of worship, houses, schools, weapons, transport, fortifications, etc. Animals seem thus to be left unprotected. ${ }^{15}$ It is true that, aside from a few multilateral treaties protecting endangered species, the welfare of animals has always been poorly regulated at the international level. ${ }^{16}$ As noted previously, this is especially valid for IHL, which is, by tradition, eminently anthropocentric. That said, the context in which IHL conventions have been adopted has significantly changed over the last decades, especially since the Vietnam War. There is today a general rise in public awareness of the necessity to improve the protection of animals whose lives are threatened by modern warfare and, in particular, by the use of certain weapons, such as mines, cluster munitions, or by the destruction of oil installations. For obvious reasons, animals cannot be assimilated into the category of 'protected persons' under IHL, thereby benefiting from the protection offered by the status of 'combatant/prisoner of war' or of 'civilian.' Indeed, as rightly pointed out by Marco Roscini, 'if they were considered combatants, animals would have not only the rights, but also the obligations associated with this status (...). ${ }^{17}$ Clearly, animals are not able to respect these obligations, which, among other things, require the capacity to distinguish persons who participate in the hostilities from those who do not or to make proportionality calculations. ${ }^{18}$ Moreover, the definition of 'civilians' mentioned in Article 50(1) of AP I only refers to 'persons. ${ }^{19}$ Thus, in order to avoid any gap in protection, animals cannot but fall within the category of objects as envisaged in IHL conventions. After all, this is consistent with the fact that, in most legal systems, animals have traditionally been considered as being 'moveable objects'. In light of this, animals could only be targeted in times of war when used for military purposes and when targeting them offers a definite military advantage. It should lastly be noted that, on a textual level, Article 54 of AP I grants a specific protection to objects that are 'indispensible for the survival of the civilian population.' This provision-which is located in Chapter III of AP I entitled 'Civilian objects' - includes livestock among these goods. This clearly confirms that certain animals are assimilated to objects by IHL. ${ }^{20}$ However, such provision-which reflects IHL utilitarian approach that values animals for what it offers to human beings and which mainly aims at preventing starvation-mostly encompasses cattle, but not many other types of animals that also deserve protection.

\footnotetext{
${ }^{15}$ Roscini, 'Animals and the Law of Armed Conflict' 2017, 46.

${ }^{16}$ Peters, 'Global Animal Law: What It Is and Why We Need It' 2016, 13-16.

${ }^{17}$ Roscini, 'Animals and the Law of Armed Conflict' 2017, 44-45.

${ }^{18}$ Nowrot, 'Animals at War' 2015, 140.

${ }^{19}$ Roscini, 'Animals and the Law of Armed Conflict' 2017, 45.

${ }^{20}$ Ibid.
} 
As to the second question, armed forces must make a proportionality calculation when launching an attack on civilian objects that might impact on animals. This calculation is a complex endeavour since it requires balancing incomparable elements: the military advantage of an attack, and the effect on civilian objects resulting from that attack. Such an exercise becomes increasingly difficult when animals may become collateral damage. ${ }^{21}$ Indeed, it depends on the value attributed to animals. In most societies, such a value judgment is contingent upon what animals offer to humankind: working tool, food, clothing, etc. It is, however, increasingly accepted that animals should also acquire value in their own right and, as a consequence, that their interests should no longer be automatically subordinated to those of human ones. A greater intrinsic value is sometimes attributed to animals whose extinction is implicated. To further complicate matters, the status of animals varies widely from one culture to another and inevitably changes over time. Moreover, a second dimension must be a factor in the proportionality test: animal considerations must be weighed against human considerations (as opposed to military advantage). ${ }^{22}$ For instance, when soldiers responsible for an attack are at risk, should these soldiers assume an increased risk in order to guarantee the protection of dogs or horses located around a military target? What should they do differently, if anything, if these animals are endangered species such as pandas or white rhinoceroses?

Without pretending to solve these issues here, three principles should guide belligerents in this regard. First, all measures should be taken to avoid any collateral damage to endangered species. This rule is grounded on the absolute necessity of sparing vulnerable animals from hostilities and other human activities that threaten them, as illustrated by the Convention on International Trade in Endangered Species of Wild Fauna and Flora, ${ }^{23}$ which prohibits unpermitted trading. Second, all measures should be taken to avoid collateral damage to animals that are necessary for the survival of the civilian population. This second rule is grounded on Article 54 of AP I referred to above that grants special protection to these types of 'objects.' Third, the welfare of all other animals, including wild animals, should be duly taken into account when undertaking a proportionality assessment, as long as soldiers launching an attack could reasonably foresee damage that could be caused to these animals. Indeed, it would be unreasonable to impose upon belligerents a duty to limit animal casualties that are, for instance, so small that they are impossible to identify. In principle, when human interests conflict with animal interests, human life or suffering should prevail over those of animals.

The third question - the treatment of animals as objects - is reductive. In many jurisdictions around the world, animals are formally recognized as 'sentient beings.'

\footnotetext{
${ }^{21}$ For an extensive analysis of the concept of proportionality in the context of the protection of the environment, see generally Schmitt, 'Green War' 1997, 55-61.

${ }^{22}$ Ibid., 58-61.

${ }^{23}$ Convention on International Trade in Endangered Species of Wild Fauna and Flora, 3 March 1973, 993 UNTS 24. It should however be noted that the application of CITES during warfare remains unclear.
} 
Of course, no state would be ready to create a new category of living beings that could limit their capacities to fight other belligerents, including armed groups. That said, in the same manner that human rights have progressively offered a series of protections to human beings in armed conflicts, ${ }^{24}$ animal rights could progressively influence the way certain existing IHL principles are interpreted and applied to animals. Three examples illustrate this proposition. First, IHL prohibits the use of means and methods of warfare that cause superfluous injury or unnecessary suffering. ${ }^{25}$ This prohibition only refers to the effect of weapons on combatants. Their impact on animals would never be taken into account so long as animals are regarded as 'inanimate objects.' Such an approach should, however, be reassessed if it is formally acknowledged that, for the purposes of IHL, animals, like any living beings, experience emotions, including pain and distress, which could be negatively affected by the use of these weapons. Second, as noted in the introduction, animals can often be used to perform military tasks, thereby making a contribution 'by their purpose or use' to military actions. When they offer a definite military advantage, these animals could, in principle, be 'destroyed', 'captured' or 'neutralized. ${ }^{26}$ Indisputably, this principle entails that, when animals previously categorised as military objectives lose the characteristics that allowed them to be so classified, they revert to being civilian objects until such time as they may again fulfil the qualification of military objective. Moreover, in the same manner that the fundamental principle of 'human dignity' prohibits the use of inhumane methods and means of warfare against combatants, a similar concept of 'animal dignity' could offer an avenue for expanding the safeguards offered to animals involved in hostilities, thereby preventing the use of indiscriminate techniques or unnecessary suffering. ${ }^{27}$ Third, should animal be treated as sentient beings or be afforded legal personality, animal welfare should also carry heavier weight in the proportionality calculation than any inanimate objects in times of armed conflict.

\section{The Protection of Individuals}

The rules, which aim at protecting injured, sick and shipwrecked persons as well as prisoners of war and civilians, were not designed for animals. Three important exceptions must, however, be mentioned. First, Article 35 of GC I provides general protection to means of transport of wounded and sick or of medical equipment. When used for that purpose, animals should benefit from this safeguard. Second,

\footnotetext{
${ }^{24}$ See generally Doswald-Beck, Human Rights in Times of Conflict and Terrorism 2012.

${ }^{25}$ AP I, 1977 (n. 5), art. 35(2). For an extensive analysis of the application of such a prohibition to animals, see generally Roscini, 'Animals and the Law of Armed Conflict' 2017, 51-56.

${ }^{26} \mathrm{AP}$ I, 1977 (n. 5), art. 52(2).

${ }^{27}$ On this basis, it could be argued that the use of animals during warfare must be prohibited at all times.
} 
Article 60 of AP I confers protection to 'demilitarized' zones between belligerents. ${ }^{28}$ This provision allows that an agreement on a demilitarized zone be tailored to each specific situation. It thus follows that the protection of areas of high global species diversity could be enhanced if belligerents were to agree to formally classifying them as 'demilitarized zones.' To this end, a Draft Convention on the Prohibition of Hostile Military Activities in Protected Areas has been developed following the 1990-1991 Gulf War in response to intensifying concerns about ecosystem damages during warfare. ${ }^{29}$ To date, however, this Convention has not received the diplomatic support needed for its adoption. It is also worth mentioning here the importance of the 1972 Convention for the Protection of the World Cultural and Natural Heritage ${ }^{30}$ in which States recognize the duty to identify and safeguard certain places that constitute part of the common heritage of humankind, including the habitat of threatened species of animals 'of outstanding universal value from the point of view of science or conservation. ${ }^{31}$ This Convention expressly states that the 'the outbreak or the threat or an armed conflict' is sufficient to place a property on the World Heritage in Danger list. ${ }^{32}$ The third exception pertains to the laws governing occupation. Article 53 of GC IV prohibits the destruction by the occupying power of private and public properties, except in cases of absolute military necessity. This provision could provide minimum protection to certain animals when considered to be items of private or public property.

The acquisition by animals of the status of 'sentient beings' should also contribute to further development of the protection of animals when they fall into the hands of belligerents. Three main avenues could be explored in this regard. First, animals, in particular protected species, should receive adequate care when wounded during hostilities, and be evacuated as soon as possible from combat zones. The nature and the extent of such obligations should vary in functions of the capacities of the belligerents and the concrete situation on the battlefield. Second, animals involved in hostilities and apprehended should be granted basic 'humane' treatments tailored to their specific needs. For instance, they should never be killed without reason. They should receive food and adequate protection and, if they can survive by themselves, be released in areas far away from the battlefield. Of course, the furniture of such treatment should never impact on the entitlements offered by IHL to human beings, which must remain a priority. Third, the obligations of occupying powers vis-à-vis animals should be clarified in IACs and expanded to NIACs where the trafficking of expensive animal products often occurs. In this regard, the provisions allowing the

\footnotetext{
${ }^{28}$ United Nations Environment Programme (UNEP), Protecting the Environment During Armed Conflict. An Inventory and Analysis of International Law (Nairobi: UNEP 2009), 20.

${ }^{29}$ Convention on the Prohibition of Military or Any Other Hostile Use of Environmental Modification Techniques (ENMOD), 10 December 1976, 1108 UNTS 151.

${ }^{30}$ Convention for the Protection of the World Cultural and Natural Heritage, 16 November 1972, 1037 UNTS 151.

${ }^{31}$ Ibid., art. 2.

${ }^{32}$ Ibid., art. 11 (4).
} 
occupying power to use occupied property without damaging or destroying it, as contained in the 1907 Hague Convention IV, ${ }^{33}$ may offer guiding principles for dealing with similar situations in NIACs. ${ }^{34}$

As we can see, the protection of animals during warfare generates many complex questions. The international community should address these issues at a time when - as a matter of fact-animals are increasingly suffering from the extreme violence of modern warfare and when - as a matter of law-their status as 'sentient beings' has been acquiring wider recognition at national level.

\section{References}

Daskin, J. H., \& Pringle, R. M. (2018, January 18). Warfare and wildlife declines in Africa's protected areas. Nature, 553, 328-332.

Doswald-Beck, L. (2012). Human rights in times of conflict and terrorism. Oxford: Oxford University Press.

Hanson, T., Brooks, T. M., Da Fonseca, G. A. B., Hoffmann, M., Lamoureux, J. F., Machlis, G., et al. (2009). Warfare in biodiversity hotspots. Conservation Biology, 23, 578-587.

Nowrot, K. (2015). Animals at War: The status of "animal soldiers" under international humanitarian law. Historical Social Research, 40, 128-150.

Peters, A. (2016). Global animal law: What it is and why we need it. Transnational Environmental Law, 5, 13-16.

Roscini, M. (2017). Animals and the law of armed conflict. Israel Yearbook on Human Rights, 47, $35-67$.

Sassòli, M. (2014). Challenges faced by non-state armed groups as regards the respect of the law governing the conduct of hostilities. In E. Geppi (Ed.), Conduct of hostilities: The practice, the law and the future (pp. 171-178). San Remo: International Institute of Humanitarian Law.

Schmitt, M. N. (1997). Green War: An assessment of the environmental law of armed conflict. Yale Law Journal, 22, 1-110.

Jérôme de Hemptinne is teaching international humanitarian law at the Universities of Louvain and Lille and at the Institut d'études politiques (Paris). He is currently a researcher at the University of Geneva. His research focuses on the qualification of armed conflicts, modes of liability in international criminal law and institutional aspects of international criminal courts and tribunals. He worked for nearly two decades at the International Criminal Tribunal for the Former Yugoslavia, at the Office of the UN Legal Counsel in New York and at the Special Tribunal for Lebanon. He is a member of the editorial committee of the Journal of International Criminal Justice.

\footnotetext{
${ }^{33}$ Convention (IV) respecting the Laws and Customs of War on Land and its annex: Regulations concerning the Laws and Customs of War on Land, 18 October 1907, 205 CTS 277.

${ }^{34}$ Convention for the Protection of the World Cultural and Natural Heritage (n. 30), 19.
} 
Open Access This chapter is licensed under the terms of the Creative Commons Attribution 4.0 International License (http://creativecommons.org/licenses/by/4.0/), which permits use, sharing, adaptation, distribution and reproduction in any medium or format, as long as you give appropriate credit to the original author(s) and the source, provide a link to the Creative Commons licence and indicate if changes were made.

The images or other third party material in this chapter are included in the chapter's Creative Commons licence, unless indicated otherwise in a credit line to the material. If material is not included in the chapter's Creative Commons licence and your intended use is not permitted by statutory regulation or exceeds the permitted use, you will need to obtain permission directly from the copyright holder. 